\title{
Práticas Integrativas e Complementares em Saúde - Emilio Telesi Júnior, Doutor em Saúde Pública, Médico Sanitarista, Especialização em Medicina Tradicional Chinesa
}

\author{
Telesi Júnior, Emilio; Carvalho, Yara Maria de; Scarcelli, Ianni Regia; Salles, \\ Sandra Abraão Chaim; Boaretto, Roberta Cristina; Schveitzer, Maria Cabral \\ Centro de Saúde Escola do Butantã, FMUSP — emiliojr@usp.br
}

Introdução: As Práticas Integrativas e Complementares em Saúde vêm gradativamente ocupando espaços no Sistema Único de Saúde (SUS). o percurso faz parte da construção de novas racionalidades em saúde, que inclui a prática regular e sistemática de ensino, a prestação de assistência e a pesquisa de natureza científica. a Portaria no. 971 do Ministério da Saúde de 03 de maio de 2.006 instituiu a Política Nacional de Práticas Integrativas e Complementares em Saúde no SUS (Brasil, 2006). Desde então são consideradas práticas integrativas, entre outras: Medicina Tradicional Chinesa (Acupuntura, práticas corporais, massoterapia, meditação), Homeopatia, Fitoterapia, Termalismo-crenoterapia, Ayuverda e Medicina Antroposófica. Parte-se do pressuposto que as PICS representam um contraponto ao padrão biologizante e medicalizante à medida que enfatizam o cuidado e a promoção da saúde. Assim, torna-se necessário, desencadear processos educativos permanentes que garantam o acesso à formação visando profissionais de saúde capacitados em PICS, comprometidos com os princípios do SUS e os da Atenção Primária à Saúde. para tanto, o Centro de Saúde Escola do Butantã "Professor Samuel Barnsley Pessoa" desenvolveu o primeiro Curso de Atualização, com quarenta horas de duração, voltado aos profissionais de saúde graduados em nível superior com interesse em ampliar os modos de pensar e intervir em saúde, com os referenciais da Medicina Tradicional Chinesa. Objetivos: Concorrer para a formação de profissionais de nível universitário, das diversas profissões de saúde, na compreensão e manejo de PICS no cotidiano das ações de cuidado, em particular na atenção primária à saúde. Método: As aulas foram planejadas e sistematizadas coletivamente, com profissionais das diferentes áreas da saúde com interesse nas PICs. no que se refere à dinâmica das aulas, elas foram conduzidas de modo a garantir a experiência e não só a teoria a respeito das práticas. Iniciávamos com a sequência completa do Tai Chi Pai Lin. E, na segunda metade, fazíamos uma roda de conversa, análise de leituras e imagens, proposta de debate e exercícios de reflexão coletiva sobre as bases conceituais da medicina tradicional chinesa, a meditação, a homeopatia e a política nacional das práticas integrativas e complementares em saúde, a relação filosofia e saúde, e também sobre os territórios e fronteiras das distintas disciplinas (psicologia, enfermagem, educação física e esporte, fisioterapia) e a medicina tradicional chinesa. Resultados: a programação foi desenvolvida a contento de todos os participantes (estudantes e docentes). Abriu caminhos para a construção de novas práticas de saúde, mais próximas da atenção de qualidade, integral e humanizada e ampliou nossa compreensão a respeito da importância de nos voltarmos para a sistematização de uma Política Estadual de Práticas Integrativas e Complementares. Parte do grupo efetivamente está empenhado em dar andamento a essa iniciativa. Conclusões: o Curso proporcionou a criação de um círculo de reflexão entre professores e alunos a respeito dos modos de aprender e praticar saúde. Contribuiu para a criação de um Coletivo Interdisciplinar no Centro de Saúde Escola do Butantã, com vistas à formação de pessoal, a assistência aos usuários e a difusão das PICS.

Telesi Júnior, Emilio; Carvalho, Yara Maria de; Scarcelli, Ianni Regia; Salles, Sandra Abraão Chaim; Boaretto, Roberta Cristina; Schveitzer, Maria Cabral. Práticas Integrativas e Complementares em Saúde - Emilio Telesi Júnior, Doutor em Saúde Pública, Médico Sanitarista, Especialização em Medicina Tradicional Chinesa. In: Anais do Congresso Internacional de Humanidades \& Humanização em Saúde [= Blucher Medical Proceedings, num.2, vol.1]. São Paulo: Editora Blucher, 2014. ISSN 2357-7282 DOI 10.5151/medpro-cihhs-10187 